\title{
Refining guidelines for the care of paediatric perioperative patients in a rural health care facility
}

Follow this and additional works at: https://www.journal.acorn.org.au/jpn

Part of the Health Services Administration Commons, Health Services Research Commons, Perioperative, Operating Room and Surgical Nursing Commons, and the Surgery Commons

(c) (i)

This work is licensed under a Creative Commons Attribution 4.0 License.

\section{Recommended Citation}

Hibberson, Michelle (2019) "Refining guidelines for the care of paediatric perioperative patients in a rural health care facility," Journal of Perioperative Nursing: Vol. 32 : Iss. 3 , Article 3.

Available at: https://doi.org/10.26550/2209-1092.1063

https://www.journal.acorn.org.au/jpn/vol32/iss3/3

This Article is brought to you for free and open access by Journal of Perioperative Nursing. It has been accepted for inclusion in Journal of Perioperative Nursing by an authorized editor of Journal of Perioperative Nursing. 


\section{Guest Editor}

Dr Paula Foran

PhD, MACN, FACORN

\section{Author}

Michelle Hibberson

MN (Anaesthetic and Recovery), CNSPeriop, RN, MACORN, MACPAN

\title{
Refining guidelines for the care of paediatric perioperative patients in a rural health care facility
}

\begin{abstract}
When reviewing and developing surgical guidelines, health care facilities need to take into account the unique challenges presented by the paediatric patient. Challenges arise from anatomical, physiological, psychological and developmental differences. An increase in paediatric patients presenting to the perioperative unit at Gippsland Southern Health Service has necessitated a review of perioperative guidelines and practices for the care of paediatric patients. The perioperative team at Gippsland Southern Health Service identified the need to improve interventions to reduce preoperative anxiety in both the parent and child. As such, nonpharmacological and, if required, pharmacological interventions were employed to reduce the incidence of preoperative anxiety. Additionally, improvements to the paediatric difficult airway box were made. Furthermore, the Paediatric Emergency Medication Bookwas obtained to reduce the likelihood of medication errors due to the weight-based non-standardised medication doses required by paediatric patients. Lastly, the perioperative team, identified that further education for the care of paediatric patients should be sought and contact was made with the Royal Children's Hospital Education Outreach Department. This review and changes to the guidelines and practices have increased safe, efficient patientcentred paediatric perioperative care.
\end{abstract}

Keywords: paediatric, children, surgery, perioperative guidelines

\section{Introduction}

Paediatric patients are not small adults'. Unique challenges present themselves when providing perioperative care for the paediatric patient due to anatomical, psychological, physiological and pharmacological differences ${ }^{2}$. Health care facilities (HCFs) need to take into account the differences between adults and children when developing paediatric surgical guidelines ${ }^{3}$.

The number of paediatric patients presenting for surgery at Gippsland Southern Health Service (GSHS) had been minimal until the appointment of a new ear, nose and throat (ENT) surgeon. This necessitated a review of the practices and guidelines used to care for paediatric patients. The review has improved and refined guidelines and practices to provide effective, safe, patient-centred paediatric perioperative care ${ }^{4}$.

Perioperative nurses reviewed practices and guidelines in preparation for the care of paediatric patients at GSHS and the following areas requiring improvements were identified:

- interventions to reduce preoperative anxiety in paediatric patients and parents

- centralising the paediatric difficult airway box

- obtaining a copy of Paediatric Emergency Medication Book 
- further education for perioperative staff on the care of paediatric perioperative patients.

\section{Terminology}

The paediatric patients cared for at GSHS can be categorised into three developmental groups:

- early childhood - two to five years of age

- middle childhood - six to eleven years of age ${ }^{5}$

- early adolescence - twelve to eighteen years of age ${ }^{5}$.

Being aware of the developmental differences of children in each of these age groups can assist the perioperative nurse to effectively care for paediatric patients ${ }^{5}$.

\section{Paediatric preoperative anxiety}

Fear of the unfamiliar perioperative environment, surgical procedures and parental separation cause more than 50 per cent of paediatric patients to experience preoperative anxiety ${ }^{6-8}$. Preoperative anxiety will manifest as crying, agitation, fighting and escape behaviour ${ }^{8}$. Increased anxiety reduces cooperation during induction of anaesthesia and is associated with the increased likelihood of emergence delirium in the Post Anaesthesia Care Unit (PACU)? Furthermore, preoperative anxiety has adverse clinical and maladaptive behavioural effects 910 . Clinical effects manifest as increased post-operative pain and analgesia consumption $n^{7,11}$. Maladaptive behavioural effects include nightmares, separation anxiety, nocturnal enuresis, sleeping problems, feeding difficulties, withdrawal and apathy ${ }^{8,10}$.

\section{Non-pharmacological management of preoperative anxiety}

Non-pharmacological techniques are the first line for managing preoperative anxiety and include preoperative education, the presence of a parent during induction of anaesthesia and distraction techniques ${ }^{8}$.

Paediatric patients and parents should have access to good quality education about their perioperative stay $^{12}$. Education improves health outcomes and reduces preoperative anxiety in both the paediatric patient and the parent ${ }^{11,13}$. Education should be in the form of written or web-based resources and should be age appropriate for the child undergoing surgery ${ }^{12,13}$. Furthermore, education can be delivered through play, orientation tours or orientation videos $^{13}$.

Ambulatory surgical services have fewer opportunities for interaction with patients and parents before the day of surgery ${ }^{14}$. This reduces the ability to deliver education about the patient's perioperative journey. A double-blinded parallel group study conducted by Hee et al.10 found that preoperative education delivered on the day of surgery did not reduce preoperative anxiety in children receiving intravenous induction of anaesthesia. In contrast, Copanitsanou and Valkeapää ${ }^{11}$ conducted a systematic review and concluded that education reduced the level of anxiety in both the paediatric patient and parent. However, Copanitsanou and Valkeapää" acknowledged that they were unable to draw conclusions about the timing of the provision of education.

Educational multimedia tools, which can be accessed prior to the day of surgery, may provide an alternative and superior form of education ${ }^{14}$. Fernandes, Arriaga and Esteves ${ }^{14}$ found in a randomised study that an educational multimedia application reduced paediatric patients' worries about surgery and also reduced parental anxiety. Similarly, Ryu et al. ${ }^{8}$ conducted a study looking at the effectiveness of a virtual reality guided tour of the operating theatre in reducing preoperative anxiety. Ryu et al. ${ }^{8}$ found that the virtual reality guided tour reduced patient anxiety and increased the paediatric patients' compliance with anaesthesia compared to conventional methods of education. The virtual reality tour was provided one hour before the patients entered the operating theatre, which contrasts with the finding of Hee et al..$^{10}$

Currently at GSHS, preoperative education is provided to patients and parents by anaesthetists, preadmission nurses and perioperative nurses prior to and on the day of surgery. In light of the evidence, the perioperative staff determined that a virtual reality tour of the theatre should be created to provide education preoperatively. Once created, this virtual reality tour will be available on the GSHS website.

Parental presence is one of the main interventions for the management of preoperative anxiety ${ }^{15}$. Parental presence reduces separation anxiety, decreases the need for premedication and will provide a positive surgical experience with superior outcomes ${ }^{16-18}$. However, parents must feel involved and safe with the perioperative care provided, otherwise parental anxiety will increase the child's anxiety ${ }^{15,17}$.

Parental presence is encouraged during the induction of anaesthesia at GSHS. During the induction of anaesthesia, the parent will provide 
comfort and reduce the anxiety of the child ${ }^{2}$. The need for a parent to accompany the child is raised by the preadmission nurse in the weeks and days before surgery to allow the parent to be prepared. Parental presence is also utilised in PACU at GSHS. The Royal College of Anaesthetists ${ }^{12}$ recommends that parents should be allowed access to PACU as soon as is appropriate. Assessment of the child is made in PACU and the parent is brought in to accompany the child as soon as possible.

In addition to parental presence, distraction techniques using video clips and video games have been successful in reducing preoperative anxiety. A study by Kim et al. ${ }^{9}$ examined the effectiveness of video games and age-appropriate video clips in reducing anxiety and increasing mask acceptance in children undergoing surgery. Kim et al. ${ }^{9}$ found that a combination of parental presence and video distraction were effective in reducing anxiety and increasing mask acceptance. Video distraction immerses the child in a familiar imaginary world, making them oblivious to the unfamiliar perioperative environment while parental presence negates separation anxiety ${ }^{9}$. Video clips and video games with parental presence have been more effective than premedication and parental presence alone as a technique to reduce anxiety in paediatric patients 9 . Paediatric patients presenting to GSHS facility will be encouraged to bring iPads and other multimedia devices with them for use up to the point of anaesthetic induction.

Non-pharmacological distraction techniques such as the use of games, toys and electronic devices can be used to reduce the likelihood of preoperative anxiety ${ }^{6}$. Distraction techniques need to be appropriate for the developmental stage of the child $^{6}$. Children can benefit from playing with and exploring the medical equipment, which reduces the anxiety caused by unfamiliarity ${ }^{6}$. Children also benefit from being able to make choices regarding their perioperative care ${ }^{6}$.

Other non-pharmacological interventions to reduce preoperative anxiety include:

- limiting the amount of monitoring applied until the patient is anaesthetised $^{2}$

- delaying intravenous cannulation until after anaesthesia ${ }^{2}$

- reducing or eliminating background noise during induction of anaesthesia ${ }^{18}$

- encouraging the patient to bring in a familiar object which gives them comfort $^{18}$

- scenting face masks with a fruity smell ${ }^{19}$

- distraction through play ${ }^{6}$.

Prior to the review, full monitoring was applied to the patient before being anaesthetised. Following a preoperative assessment with the anaesthetist, healthy, low risk children only have an oxygen saturation probe for induction. Full monitoring is applied immediately after the patient loses consciousness. Also, most paediatric patients will have a gas induction allowing intravenous cannulation to be performed when the child has been anaesthetised. All surgical counts are completed before the patient enters the theatre to reduce background noise and the theatre lights are dimmed slightly to reduce over stimulation. Patients get to choose from four scented chapsticks, and these are used to scent the anaesthetic mask and the child is given the mask to hold on the way into the theatre. Furthermore, distraction through play is used for the appropriate age groups. The child is asked if they would like to be a 'deep-sea diver' or 'astronaut' and their anaesthetic mask becomes part of that make-believe experience.

\section{Pharmacological management of preoperative anxiety}

Premedication is used to reduce preoperative anxiety and aims to produce a calmer more cooperative child, making induction of anaesthesia smoother ${ }^{7,20}$. Midazolam has been used as the most common premedication; however, it has a bitter taste and can produce long-term behavioural issues, hiccups, paradoxical reactions, respiratory depression and cognitive impairment ${ }^{7,20}$. Clonidine, a centrally acting alpha-2 agonist, reliably produces anxiolysis and is becoming the preferred premedication to manage preoperative anxiety in paediatric patients $20-22$.

A meta-analysis conducted by Dahmani et al. ${ }^{23}$ found that clonidine was superior to midazolam as a premedication and reduced postoperative pain and emergence delirium. In contrast, a study by Trevor et al. ${ }^{7}$ demonstrated that midazolam was superior to clonidine for preoperative anxiolysis. However, Trevor et al.? highlighted the other benefits of clonidine, which make it a preferred premedication for paediatric patients. These benefits include reduced anaesthetic requirements, post-operative analgesic effects, reduced postoperative nausea and vomiting and shivering, and reduced incidence of emergence delirium?

A study conducted by Mitra, Kazal and Anand ${ }^{22}$ found that both intranasal clonidine and midazolam produced anxiolysis. However, mask acceptance was greater in the clonidine group, and patients administered clonidine 
woke better than those given midazolam. Mitra, Kazal and Anand ${ }^{22}$ also highlight the other benefits of clonidine, which provides postoperative analgesia, reduces the incidence of post-operative nausea and vomiting and attenuates postoperative delirium ${ }^{22}$.

A study conducted by Kumari et al. ${ }^{20}$ compared the effectiveness of midazolam, clonidine and dexmedetomidine as a premedication in children. All three medications produced effective anxiolysis, sedation, mask acceptance and separation from parents ${ }^{20}$. However, midazolam was superior to clonidine and dexmedetomidine as there was a faster onset of action, greater sedation, easier separation from parents and excellent mask acceptance $^{20}$. Despite this, Kumari et al. ${ }^{20}$ concluded that all three drugs are suitable premedications for children undergoing surgery.

Previously midazolam was used as a premedication at GSHS. However, discussions with the anaesthetists have led to clonidine being ordered as a premedication for paediatric patients undergoing ENT surgery. The additional benefits of postoperative analgesia reduced postoperative nausea and vomiting, and reduced rates of post-operative delirium are the reason for the preference to prescribe clonidine as a premedication. However, the effectiveness of clonidine to reduce the incidence of preoperative anxiety and emergency delirium at GSHS is still being assessed.

\section{Difficult airway box}

Airway management in the paediatric patient is challenging due to natural anatomical differences ${ }^{18}$ from adult patients. These include a large head with a prominent occiput, small mouth, a broad and short tongue, a short and slender neck and a more superior larynx with a sharper angle between the tongue and the glottis ${ }^{1,24}$. There is also physiological narrowing of the vocal cords and a long narrow epiglottis ${ }^{1,24}$. Furthermore, children have a higher oxygen consumption with a lower oxygen reserve and therefore a lower tolerance for respiratory interruptions ${ }^{1,24}$.

Facilities catering predominantly for adult patients should set up a paediatric cart that contains the appropriate equipment for paediatric patients ${ }^{18}$. Additionally, a paediatric difficult airway cart should be available and stocked with the appropriate equipment for managing a difficult airway ${ }^{3}$. This equipment should include a video laryngoscope, a fibre-optic and rigid bronchoscope, optical stylets and supraglottic airways ${ }^{3,5}$.

Equipment for the management of paediatric difficult airways was available in the perioperative unit at GSHS but not centralised. After review of the guidelines, a dedicated difficult airway box for paediatric patients was created and placed on the difficult airway trolley. Additionally, size two laryngoscope blades were obtained for use with the perioperative unit's video laryngoscope.

\section{Paediatric emergency medication schedule}

Meticulous attention needs to be taken when preparing medications for administration to paediatric patients ${ }^{25}$. Medication errors during anaesthesia for paediatric patients are higher due to weightbased non-standardised dosing ${ }^{26}$. Additionally, the need to dilute stock to administer small quantities of medication is a potential source of errors $^{27}$. Medication calculations are also a source of error, therefore, charts which list the standardised emergency medication doses can reduce errors ${ }^{4,25,28}$. Polander et al. state that a written schedule for emergency resuscitation drugs is an essential part of the paediatric equipment which should be available in HCFs conducting paediatric surgery.

\section{A copy of Paediatric Emergency} Medication Book was obtained from the Monash Children's Hospital to allow for the efficient and safe preparation and administration of emergency medications at GSHS.

\section{Perioperative nurse education}

Adequate numbers of appropriately trained staff should be available to care for paediatric patients ${ }^{29}$. Due to the specialised nature of paediatric anaesthesia, anaesthetic nurses must receive education in the care of paediatric patients ${ }^{2,30}$. Furthermore, PACU nurses have a ratio of one nurse to one paediatric patient ${ }^{31}$ and are also required to have education and experience in the care of paediatric patients at all stages of post-operative care ${ }^{3,32}$. Tailored paediatric training is available through the Royal Children's Hospital Education Outreach Program ${ }^{33}$. This enables access to education and training as well as the formation of partnerships with a large metropolitan hospital, thereby giving rural families the option to have surgery closer to home ${ }^{33}$.

Contact was made with the Royal Children's Hospital Education Outreach Department and access to an education program tailored for the anaesthetists, perioperative nurses and ward nurses was gained.

\section{Conclusion}

Small changes were made to the guidelines and practices in the perioperative unit at GSHS to increase safety when caring for paediatric patients requiring ENT 
surgery. Increased knowledge of the benefits of non-pharmacological strategies and clonidine as a premedication has led to reduced preoperative anxiety. A difficult airway box has been created, Paediatric Emergency Medicine Book obtained and education organised for the perioperative staff at GSHS. These measures have increased the safe delivery of efficient patientcentred paediatric perioperative care at GSHS.

\section{Acknowledgements}

This paper was submitted to the University of Tasmania as Assessment Three for CNA803 Advanced Clinical Nursing Practice. Furthermore, I would like to acknowledge the perioperative team at Gippsland Southern Health Service whose knowledge, teamwork and commitment to the improvement of patient safety enabled the review and implementation of changes to practices and guidelines for the care of paediatric perioperative patients.

I would also like to acknowledge $\mathrm{Dr}$ Paula Foran, unit coordinator and tutor for CNA803 Advance Clinical Nursing Practice for her expert guidance and assistance.

\section{References}

1. Harless J, Ramaiah R, Bhananker SM. Pediatric airway management. Int J Crit IIIn Inj Sci 2014;4(1):65-70.

2. McDougall R, Skinner A. Pediatric Anaesthesia, Chapter 21. In: Harley I, Hore P (eds). Anaesthesia: An Introduction. $5^{\text {th }}$ ed. East Hawthorn: IP Communications; 2012, 250-266.

3. Polander DM, Houck CS, Tobias J, Agarwal $\mathrm{R}$, Anderson C, Bannister C et al. Critical elements for the pediatric perioperative anesthesia environment. Pediatrics 2015;136(6):1200-1205. doi:10.1542/peds.20153595.

4. Johnson Q, McVey J. Enhancing pediatric perioperative patient safety. AORN J 2017;106(5):434-442. doi:10.1016/j. aorn.2017.09.007.
5. Derieg S. An overview of perioperative care for pediatric patients. Journal of Perioperative Nursing 2017;30(3):23-29. doi:10.26550/303/23-29.

6. Panella JJ. Preoperative care of children: Strategies from a child life perspective. AORN J 2016;104(1):11-22. doi:10.1016/j. aorn.2016.05.004

7. Trevor S, Upadya M, Sinha C, Kaur M. A comparison of midazolam and clonidine as oral premedication in pediatric patients. Saudi J Anaesth 2012;6(1):8-11.

8. Ryu JH, Park SJ, Park JW, Kim JW, Yoo HJ, Kim TW et al. Randomized clinical trial of immersive virtual reality tour of the operating theatre in children before anaesthesia. BJS Open 2017;104(12):16281633. doi:10.1002/bjs.10684.

9. Kim H, Jung SM, Yu H, Park SJ. Video distraction and parental presence for the management of preoperative anxiety and post-operative anxiety and post-operative behavioural disturbance in children: A randomized controlled trial. Anaesth Analg 2015;121(3):778-784. doi:10.1213/ ANE.0000000000000839.

10. Hee HI, Lim EHL, Tan QC, Bao ZY, Loh KWT. Effect of preoperative education on behaviour of children during induction of anaesthesia: A randomised clinical trial of efficacy. Anaesth Intensive Care 2012;40(5):795-802. doi:10.1177/0310057X1204000507

11. Copanitsanou P, Valkeapää K. Effects of education of paediatric patients undergoing elective surgical procedures on their anxiety- a systematic review. J Clin Nurs 2014;23:940-954. doi:10.1111/jocn.12187.

12. Royal College of Anaesthetists (RCOA). Chapter 10 Guideline for the provision of anaesthesia services (GPAS) Guidelines for the provision of paediatric anaesthesia services 2019 [Internet]. London: RCOA; 2019 [updated January 2019; cited 2019 May 20]. Available from: www.rcoa.ac.uk/system/ files/GPAS-2019-10-PAEDIATRICS.pdf.

13. McCullagh C, Lee T. Chapter 7: Assessment and preparation for surgery. In: Hamlin L, Davies M, Richardson-Tench M, SutherlandFraser $S$ (eds). Perioperative nursing: An introduction. 2nd ed. Chatswood: Elsevier; 2016, 160-192.

14. Fernandes S, Arriaga P, Esteves F. Using an educational multimedia application to prepare children for outpatient surgeries. Health Commun 2015;30(12):1190-1200. doi:10. 1080/10410236.2014.896446.

15. Chorney JM, Kain ZN. Family-centered pediatric perioperative care. Anesthesol 2010;112(3):751-755. doi:10.1097/ ALN.0b013e3181cb5ade.
16. Terry KL, Crego N. Addressing differences and challenges in the pediatric perioperative setting. AORN J 2016;104(1):1-3. Available from: doi:10.1016/j.aorn.2016.05.012.

17. Sjöberg C, Svedberg P, Nygren JM, Carlsson IM. Participation in paediatric perioperative care: 'What it means for parents'. J Clin Nurs 2017;26(23-24):4246-4254. doi:10.1111/ jocn.13747.

18. Difusco LA. Chapter 26, Pediatric surgery. In: Rothrock JC, McEwen D (eds). Alexander's Care of the Patient in Surgery. $15^{\text {th }}$ ed. St. Louis: Elsevier Mosby; 2015:1008-1080.

19. Walters J, Kumar Z. Chapter 8, Patient care during anaesthesia. In: Hamlin L, Davies M, Richardson-Tench M, Sutherland-Fraser S (eds). Perioperative nursing: An introduction. 2nd ed. Chatswood: Elsevier; 2016:193-231.

20. Kumari S, Agrawal N, Usha G, Talwa V, Gupta P. Comparison of oral clonidine, oral dexmedetomidine, and oral midazolam for premedication in pediatric patients undergoing elective surgery. Anesth Essays Res 2017;11:185-191. doi:10.4103/02591162.194586

21. Larsson $P$, Nordlinder A, Bergendahl HTG, Lönnqvist PA, Eksborg S, Almenrader N et al. Oral bioavailability of clonidine in children. Pediatr Anaesth 2011;21(3):335-340. doi:10.1111/j.1460-9592.2010.03397.x.

22. Mitra S, Kazal S, Anand LK. Intranasal clonidine vs. midazolam as premedication in children: A randomized controlled trial. Indian Peadiatr 2014;51(2):113-118.

23. Dahmani S, Brasher C, Stany I, Golmard J, Skhiri A, Bruneau B et al. Premedication with clonidine is superior to benzodiazepines. A meta-analysis of published studies. Acta Anaesthesiol Scand 2010;54(4):397-402. doi:10.1111/j.1399-6576.2009.02207.x.

24. Walas W, Aleksandrowicz D, BorszewskaKornacka M, Gaszynski T, Helwich E, Magdal $M$ et al. Unanticipated difficult airway management in children - the consensus statement of the Paediatric Anaesthesiology and Intensive Care section and the Airway Management Section of the Polish Society of Anaesthesiology and Intensive Therapy and the Polish Society of Neonatology. Anaesth Inten Therapy 2017;49(5):336-349. doi:10.5603/AIT.2017.0079.

25. Bester K, Meyer H, Crowther M, Gray R. Anaesthesia for paediatric patients: Minimising the risk. SAMJ 2018;108(6):457459. doi:10.7196/SAMJ.2018.v108i6.13351.

26. Lobaugh LMY, Martin LD, Schleelein LE, Tyler DC, Litman RS. Medication errors in pediatric anesthesia: A report from the wake-up safe quality improvement initiative. Anesth Analg 2017;125(3):936-942. doi:10.1213/ ANE.0000000000002279. 
27. Kahn $\mathrm{S}$, Abramson EL. What is new in paediatric medication safety? Arch Dis Child 2019;104(6):596-599. doi:10.1136/ archdischild-2018-315175.

28. Kanjia MK, Adler AC, Buck D, Varughese AM. Increasing compliance of safe medication administration in pediatric anesthesia by use of standardized checklist. Peadiatr Anaesth 2019;29(3):258-264. doi:10.1111/ pan.13578.

29. Australian and New Zealand College of Anaesthetists (ANZCA). PS29 Statement on anaesthesia care of children in health care facilities without dedicated paediatric facilities [Internet]. Melbourne: ANZCA; 2008 [updated August 2008; cited 2019 May 20]. Available from: www.anzca.edu.au/ documents/ps29-2008-statement-onanaesthesia-care-of-childre.pdf.
30. Australian and New Zealand College of Anaesthetists. PS08 The assistant to the anaesthetist ANZCA [Internet]. Melbourne; ANZCA; 2017 July, 24. Available from: www.anzca.edu.au/documents/ps08-2015statement-on-the-assistant-for-the-anaes.

31. Australian College of Perianaesthesia Nurses (ACPAN). Standards for Perioperative Nurses in Australia. $15^{\text {th }}$ Edition. Statement on staffing in stage 1 PACU 2018. ACPAN; 2018 [cited 2019 July 14]. Available from: acpan.edu.au/wp-content/uploads/2018/11/ OCTOBER-2018-ACPAN-Statement-1.pdf.
32. Australian and New Zealand College of Anaesthetists. PSO4 Statement on the Post-Anaesthesia Care Unit (Pilot) ANZCA [Internet]. Melbourne: ANZCA; 9 May 2019. Available from: www.anzca.edu.au/ documents/ps04bp-statement-on-the-postanaesthesia-care-unit.pdf.

33. The Royal Children's Hospital Melbourne (RCH). Education outreach program [Internet]. Melbourne: RCH; 2019 [cited 2019 May 20]. Available from: www.rch.org. au/allied-health-and-nursing/educationoutreach. 